Check for updates

Cite this: RSC Adv., 2019, 9, 37467

Received 20th August 2019

Accepted 8th November 2019

DOI: $10.1039 / c 9 r a 06539 c$

rsc.li/rsc-advances

\section{First-principles study of vanadium carbides as electrocatalysts for hydrogen and oxygen evolution reactions $\uparrow$}

\author{
Jing Wan, (D) ${ }^{\mathrm{ab}}$ Congcong Wang, ${ }^{\mathrm{a}}$ Qian Tang, ${ }^{\mathrm{a}}$ Xiao $\mathrm{Gu}^{\star \mathrm{b}}$ and Mingquan $\mathrm{He}$ (D) *a
}

Vanadium carbides have attracted much attention as highly active catalysts in both the hydrogen evolution reaction (HER) and oxygen evolution reaction (OER), while a satisfactory understanding of the underlying mechanisms still remains a challenge. Herein we apply first-principles calculations to systematically analyze the crystal structures, electronic properties, free energies during the HER and OER processes, surface energies and crystal formation energies of the three types of vanadium carbides, i.e., $V_{4} C_{3}, V_{8} C_{7}$ and VC. We show that all these vanadium carbides are metallic, which enables efficient electron transport from the bulk to the surface of the catalysts. All these vanadium carbides exhibit excellent HER performance but show poor OER catalytic activity. In particular, the $\mathrm{V}_{8} \mathrm{C}_{7}$ (110) surface shows the best catalytic performance for its relatively small $\left|\Delta G\left(\mathrm{H}^{*}\right)\right|$ value $(-0.114 \mathrm{eV})$ for $\mathrm{HER}$. Emergence of natural carbon vacancies gives rise to large surface energy, proper hydrogen adsorption energy, low crystal formation energy and weak bond strength in $V_{8} V_{7}$, which guarantees its leading position among the three vanadium carbides. In addition, a remarkable resemblance between $V C / V_{8} C_{7}$ and $P t$ in their electronic structures on (110) and (111) surfaces are found, which indicates a Pt-like HER mechanism in these vanadium carbides. Our results thus bring new insights to the theoretical understanding of the excellent HER performance of vanadium carbides.

\section{Introduction}

Large-scale consumption of fossil fuels has brought great harm to the environment, for instance, air pollution and global warming. ${ }^{1}$ Developing renewable energy sources is a feasible method to alleviate human reliance on fossil fuels. Hydrogen is a clean, renewable and abundant energy carrier compared to carbon-based fuels. ${ }^{2}$ Numerous methods have been developed to produce hydrogen, among which the hydrogen evolution reaction (HER) via water electrolysis has attracted considerable attention due to its low cost and environmental benignity. As is well known, noble metal-based materials, like Pt, Ru, and Pd, are the most ideal electrocatalysts to date. However, their limited availability, high cost, and scarcity hinder their commercial applications. ${ }^{3-5}$ Consequently, the quest to search for inexpensive, highly active and earth-abundant electrocatalysts is highly demanded.

${ }^{a}$ Chongqing Key Laboratory of Soft Condensed Matter Physics and Smart Materials, College of Physics, Chongqing University, Chongqing 401331, China. E-mail: mingquan.he@cqu.edu.cn

${ }^{b}$ School of Physical Science and Technology, Ningbo University, Ningbo 31500o, China. E-mail: guxiao@nbu.edu.cn

$\dagger$ Electronic supplementary information (ESI) available. See DOI: $10.1039 / \mathrm{c} 9 \mathrm{ra} 06539 \mathrm{c}$
Transition metal carbides (TMC) have been widely investigated as HER catalysts for good electrical conductivity, wide $\mathrm{pH}$ applicability, low cost, and high durability. ${ }^{6-11} \mathrm{Hu}$ and Leonard's group synthesized several types of molybdenum carbides and, in particular, $\beta-\mathrm{Mo}_{2} \mathrm{C}$ exhibit high catalytic activity. ${ }^{12,13}$ Our previous theoretical study also confirmed that $\beta-\mathrm{Mo}_{2} \mathrm{C}$ has low $\left|\Delta G\left(\mathrm{H}^{*}\right)\right|$ value $(0.089 \mathrm{eV})$, which is close to that of Pt $(-0.085$ $\mathrm{eV}$ ) and is therefore named as Pt-like catalyst. ${ }^{\mathbf{1 4}}$ Tungsten carbide, another important transition metal carbide, was first found to show Pt-like catalytic characters. ${ }^{15}$ Wirth et al. systematically studied IVB-VIB transition metal carbides as HER catalysts in acidic condition, among which tungsten carbide displayed the best catalytic performance, and even better than molybdenum carbide. ${ }^{16} \mathrm{VB}$ metal carbides, especially vanadium carbides $\left(\mathrm{VC}, \mathrm{V}_{8} \mathrm{C}_{7}\right)$, have attracted extensive attention due to their higher natural abundance and lower cost compared to the aforementioned metals. ${ }^{17,18}$ Recently, Jin et al. reported a substrate-mediated method to grow vanadium carbide (VC), which was considered as high performance electrocatalysts for dye-sensitized solar cells. ${ }^{19}$ Peng et al. synthesized vanadium carbide nanoparticles encapsulated in graphitic carbon network (VC-NS) by hydrothermal reaction and subsequent low-temperature magnesium thermic reaction. ${ }^{20}$ Its HER performance is comparable to $20 \% \mathrm{Pt} / \mathrm{C}$, due to small overpotential $\left(98 \mathrm{mV}\right.$ ) and Tafel slope (56 $\left.\mathrm{mV} \mathrm{dec}^{-1}\right)$. Meanwhile, $\mathrm{V}_{8} \mathrm{C}_{7}$ nanoparticles were prepared by Yagya N. Regmi 
et al., which show excellent HER and oxygen reduction reaction (ORR) activity. ${ }^{21}$ Particularly, Xu et al. developed a single crystalline $\mathrm{V}_{8} \mathrm{C}_{7}$ networks, displaying high HER activity in all $\mathrm{pH}$ conditions, and even better than Pt@C in alkaline solution (the overpotential of $\mathrm{V}_{8} \mathrm{C}_{7}$ and $\mathrm{Pt} @ \mathrm{C}$ are $47 \mathrm{mV}$ and $49 \mathrm{mV}$ in alkaline solution, respectively). ${ }^{22}$ So far, plenty of works have shown that vanadium carbides, $\mathrm{VC}$ and $\mathrm{V}_{8} \mathrm{C}_{7}$, can be used as highly active catalysts both in HER and OER. Despite intensive studies, the underlying mechanisms responsible for the excellent catalytic performance of these vanadium carbides are, however, still elusive.

In this work, we employed first-principles calculations to systematically analyze the crystal structures, electronic properties, free energies of HER and OER process, surface energies and formation energies of three types of vanadium carbides, i.e., $\mathrm{V}_{4} \mathrm{C}_{3}, \mathrm{~V}_{8} \mathrm{C}_{7}$ and VC. Smallest free energy $\left|\Delta G\left(\mathrm{H}^{*}\right)\right|$ value is found in $\mathrm{V}_{8} \mathrm{C}_{7}$ and thus it exhibits the best HER catalytic performance among these vanadium carbides. Its outstanding achievement can be explained by its large surface energy, proper hydrogen adsorption energy, low crystal formation energy (enhanced specific surface area and more active sites) and weak bond strength. Furthermore, the calculated density of states (DOS) suggest that $\mathrm{V}_{8} \mathrm{C}_{7}$ and $\mathrm{VC}$ (110) and (111) surfaces have homologous d-band structures with Pt (110) and (111) surfaces, implying their Pt-like HER mechanism.

\section{Methodology}

\subsection{Computational details}

The first-principles calculations were performed by the Vienna $a b$ initio simulation package (VASP) $\operatorname{code}^{23}$ based on the density functional theory (DFT) method. Projector augmented wave (PAW) based potentials were used to describe the interactions between valence electrons and ion cores. PerdewBurke-Ernzerhof (PBE) in the generalized gradient approximation (GGA) was used to treat the exchangecorrelation interactions..$^{24,25}$ The structures optimization was achieved up to a precision of $10^{-5} \mathrm{eV}$ in total energy difference, and the Hellman-Feynman forces converged to $0.01 \mathrm{eV} \AA^{-1}$ on each atom. The Kohn-Sham orbitals were expanded in plane waves with cut-off energy of $500 \mathrm{eV}$. The Brillouin zone integration and $k$-point sampling were performed with a Monkhorst-Pack scheme ${ }^{26}$ of a $4 \times 4 \times 4$ and $4 \times$ $4 \times 2$ grid for bulk and slab model of vanadium carbons, and the slab thickness was set as $15 \AA$. . The reaction barriers energies of water decomposition were explored by using the climbing image nudged elastic band (CI-NEB) method. ${ }^{27}$

In this work, the adsorption energies were calculated by:

$$
E_{\mathrm{ads}}=E_{(\mathrm{slab}+i)}-E_{\mathrm{slab}}-E_{i}
$$

where $E_{\text {ads }}, E_{(\mathrm{slab}+i)}, E_{\text {slab }}$ and $E_{i}$ are adsorption energy, total energy of species adsorbed on the slab, total energy of slab and total energy of adsorbed species, respectively. In this study, the energy of an $\mathrm{H}$ atom $\left(E_{\mathrm{H}}\right)$ is equal to $\frac{1}{2} E_{\mathrm{H}_{2}}$.

Gibbs free energy $\Delta G\left(i^{*}\right)$ was calculated $\operatorname{as}^{28}$

$$
\Delta G\left(i^{*}\right)=\Delta E\left(i^{*}\right)+\Delta \mathrm{ZPE}\left(i^{*}\right)+T \Delta S\left(i^{*}\right)
$$

where $\Delta E\left(i^{*}\right)$ is adsorption energy, $\Delta \mathrm{ZPE}\left(i^{*}\right)$ is the changes in zero point energy. ZPE was calculated through frozen phonon approach, which can be estimated by ZPE $=1 / 2\left[\sum h \nu_{i}\right]$, where $h$ and $\nu_{i}$ are Planck constant and zone center vibrational frequencies of the system $;{ }^{29} T \Delta S\left(i^{*}\right)$ is entropic contribution at standard condition ( $T=298 \mathrm{~K}$ and $P=1 \mathrm{bar}$ ), as listed in CRC Handbook.

The surface activity can be described by surface energy. The larger the surface energy, the higher the activity. Surface energy is given by:

$$
E_{\text {surf }}=\frac{E_{\text {slab }}-N E_{\text {bulk }}}{2 A}
$$

where $E_{\text {slab }}$ is the total energy of the slab model, $N$ is the number of vanadium carbides units in the slab, $E_{\text {bulk }}$ is the total energy of bulk cell with the same number of units, and $A$ is the surface area of the slab.

Crystal formation energy is based on:

$$
\Delta E_{\mathrm{f}}\left(\mathrm{V}_{x} \mathrm{C}_{y}\right)=\frac{E_{\mathrm{V}_{x} \mathrm{C}_{y}}-x E_{\mathrm{V}}-y E_{\mathrm{C}}}{x+y}
$$

where $\Delta E_{\mathrm{f}}\left(\mathrm{V}_{x} \mathrm{C}_{y}\right)$ is crystal formation energy, $E_{\mathrm{V}_{x} \mathrm{C}_{y}}$ is the total energy of vanadium carbons. $E_{\mathrm{V}}$ and $E_{\mathrm{C}}$ are total energies per atom in metallic vanadium and graphite, respectively.

\subsection{Crystal structures of vanadium carbides}

The crystal structure of VC belongs to the cubic rock salt family ( $\mathrm{NaCl}$ type, $F m \overline{3} m$ ), which contains 8 atoms ( $4 \mathrm{~V}$ atoms, $4 \mathrm{C}$ atoms) per unit cell. To theoretically study the effects of carbon vacancies, we artificially built up a compound $\mathrm{V}_{4} \mathrm{C}_{3}$ using the same cubic structure but with 1 carbon vacancy per unit cell (7 atoms including $4 \mathrm{~V}$ atoms and $3 \mathrm{C}$ atoms). The emergence of natural carbon vacancies in $\mathrm{V}_{8} \mathrm{C}_{7}$ alters the space group to $\mathrm{P}_{3} 32$ and the number of atoms counts up to 60 (32 V atoms, $28 \mathrm{C}$ atoms) in one unit cell. But the structure still remains cubic in general. In order to compare these compounds effectively, $2 \times 2$ $\times 2$ supercell for $\mathrm{V}_{4} \mathrm{C}_{3}(32 \mathrm{~V}$ atoms, $24 \mathrm{C}$ atoms) and $\mathrm{VC}(32 \mathrm{~V}$ atoms, $32 \mathrm{C}$ atoms), one unit cell for $\mathrm{V}_{8} \mathrm{C}_{7}(32 \mathrm{~V}$ atoms, $28 \mathrm{C}$ atoms) are used in the calculations such that each block contains the same amount of $\mathrm{V}$ atoms for all these three materials, as shown in Fig. 1. One can see that $\mathrm{V}$ and $\mathrm{C}$ atoms form $\mathrm{VC}_{6}$ octahedral structure. Clearly, $\mathrm{V}_{4} \mathrm{C}_{3}$ and $\mathrm{V}_{8} \mathrm{C}_{7}$ have $8 \mathrm{C}$ atoms and $4 \mathrm{C}$ atoms vacancies per block, respectively. Tables 1 and $\mathrm{S} 1 \uparrow$ illustrate the lattices and sites information of vanadium carbides. The lattice parameters of $\mathrm{V}_{4} \mathrm{C}_{3}, \mathrm{~V}_{8} \mathrm{C}_{7}$ and VC are 8.219 $\AA$ A, 8.315 $\AA$, and $8.305 \AA$, respectively, which are in good agreement with theoretical and experimental works. ${ }^{30}$ Due to the appearance of artificial carbon vacancies, the lattice constants of $\mathrm{V}_{4} \mathrm{C}_{3}$ is smaller than VC. On the other hand, formation of natural carbon vacancies changes the space group in the real material $\mathrm{V}_{8} \mathrm{C}_{7}$, which produces slightly larger lattice constant.

\section{Results and discussion}

To unveil the electrical conductivity of vanadium carbides, we firstly calculated their total and partial density of states (DOS), 
(a)

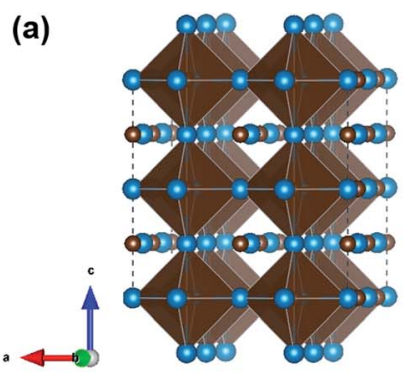

(b)

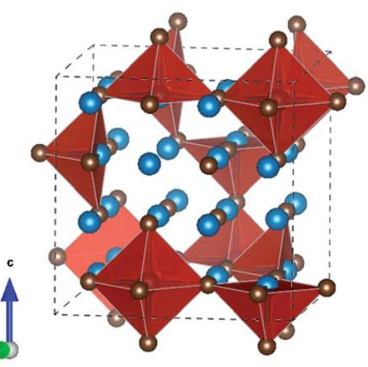

(c)

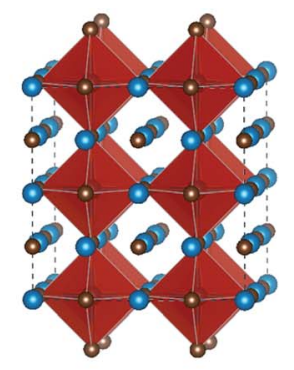

Fig. 1 Crystal structures of vanadium carbides, (a) $V_{4} C_{3}$, (b) $V_{8} C_{7}$, (c) VC. Blue and brown balls are $V$ and $C$ atoms, respectively.

Table 1 Lattice information of $\mathrm{V}_{4} \mathrm{C}_{3}, \mathrm{~V}_{8} \mathrm{C}_{7}$ and $\mathrm{VC}$

\begin{tabular}{llll}
\hline & $a=b=c(\AA)$ & $\alpha=\beta=\gamma\left({ }^{\circ}\right)$ & Space group \\
\hline $\mathrm{V}_{4} \mathrm{C}_{3}$ & 8.219 & $90^{\circ}$ & $F m \overline{3} m$ \\
$\mathrm{~V}_{8} \mathrm{C}_{7}$ & 8.315 & $90^{\circ}$ & $P 4_{3} 32$ \\
$\mathrm{VC}$ & 8.305 & $90^{\circ}$ & $F m \overline{3} m$
\end{tabular}

as shown in Fig. 2. From which we can see that these vanadium carbides have similar DOS structures, and all of them exhibit metallic character. The DOS structures can be divided into two regions. The first region is from $-8 \mathrm{eV}$ to $-2 \mathrm{eV}$, where $\mathrm{C} 2 \mathrm{p}$ and V 3d orbits form strong hybrid covalent bonds. Between

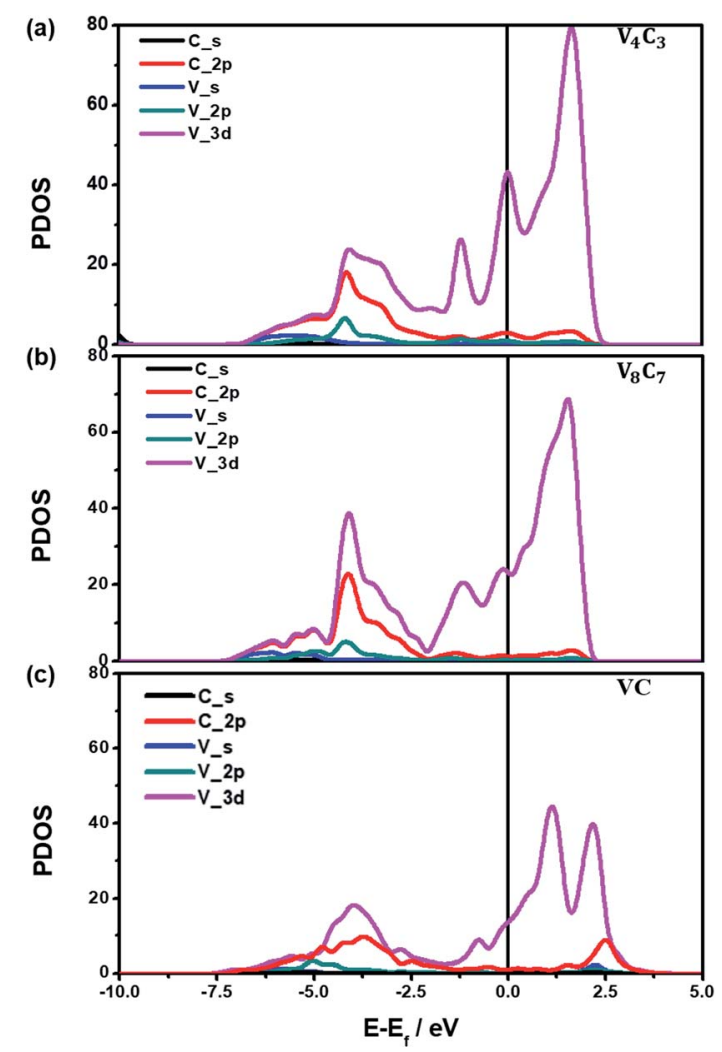

Fig. 2 Projected density of state (PDOS) of vanadium carbides, (a) $\mathrm{V}_{4} \mathrm{C}_{3}$, (b) $\mathrm{V}_{8} \mathrm{C}_{7}$, (c) $\mathrm{VC}$.
$-2 \mathrm{eV}$ and $3 \mathrm{eV}$ near the Fermi level, is the second region, which is mainly occupied by $3 \mathrm{~d}$ orbit of $\mathrm{V}$ atoms. This implies that conductive electrons are mainly transferred from bulk $\mathrm{V}$ atoms to surface during HER process. Furthermore, to investigate the properties of surface states, the electronic structure of these vanadium carbides surfaces $(001,110,111)$ were also evaluated (see Fig. S1 $\dagger$ ). All of these surface states show metallic behavior, which ensures the efficient transportation of electrons from the bulk to the surfaces of these materials.

Fig. 3(a) presents the total reaction process of HER in acidic condition: $2 \mathrm{H}^{+}+2 \mathrm{e}^{-} \rightarrow \mathrm{H}_{2}$. There are two possible reaction steps in HER, the first step is called Volmer, and the second step is the generation of hydrogen (Tafel step or Heyrovsky step). The details of HER process can be found in Section 1 of ESI. $\dagger$ The Gibbs free energy difference between the final state and initial state $\left|\Delta G\left(\mathrm{H}^{*}\right)\right|$ is usually regarded as a good descriptor for HER process $^{31}$ and can be computed by $\Delta G\left(\mathrm{H}^{*}\right)=\Delta E\left(\mathrm{H}^{*}\right)+\Delta \mathrm{ZPE}\left(\mathrm{H}^{*}\right)$ - $T \Delta S\left(\mathrm{H}^{*}\right)$ (see ESI† Section 1 for calculation details). Small values of $\left|\Delta G\left(\mathrm{H}^{*}\right)\right|$ in the vicinity of zero are expected for a highperformance catalyst. In Fig. 3(b), we present the minimum $\Delta G\left(\mathrm{H}^{*}\right)$ values calculated among the three surfaces (001), (110), (111) for $\mathrm{V}_{4} \mathrm{C}_{3}, \mathrm{~V}_{8} \mathrm{C}_{7}$ and $\mathrm{VC}$. The complete sets of results for all three surfaces of the three systems are shown in Tables S2-S4 and Fig. S2. $\dagger$ For $\mathrm{V}_{4} \mathrm{C}_{3}$, its (001) surface shows the smallest $\Delta G\left(\mathrm{H}^{*}\right)$ value $(0.165 \mathrm{eV})$, whereas the (110) surface has better performance for $\mathrm{V}_{8} \mathrm{C}_{7}$ and $\mathrm{VC}$ in good agreement with experimental studies. ${ }^{22}$ Moreover, our calculation also indicates that $\mathrm{V}_{8} \mathrm{C}_{7}$ has the lowest $\left|\Delta G\left(\mathrm{H}^{*}\right)\right|$ magnitude among these three vanadium carbides(see Fig. $3(\mathrm{~b})$ ), which confirms that $\mathrm{V}_{8} \mathrm{C}_{7}$ is the most effective HER catalyst in these compounds.

Generally, HER process in the alkaline environment is poorly understood. As shown in Fig. 3(c), the HER process in an alkaline media can be expressed as $2 \mathrm{H}_{2} \mathrm{O}+2 \mathrm{e}^{-}+*=\mathrm{H}_{2}+2 \mathrm{OH}^{-}$. Similar to acidic media, two reaction steps called Volmer and Tafel or Heyrovsky take place in a typical process (see ESI $\dagger$ Section 2 for more details). Volmer step: $\mathrm{H}_{2} \mathrm{O}+\mathrm{e}^{-}+*=\mathrm{H}^{*}+$ $\mathrm{OH}^{-}$, usually plays a momentous role during HER. Consequently, we adopt the water decomposition barrier energy as the descriptor for HER. The smaller barrier energy is, the better performance of a catalyst has. The calculated energy barriers on $\mathrm{V}_{4} \mathrm{C}_{3}$ (001), $\mathrm{V}_{8} \mathrm{C}_{7}$ (110) and $\mathrm{VC}$ (110) surfaces are displayed in Fig. 3(d). One can find that the water decomposition consists of an initial state (IS), three transition states (TS) and a final state (FS). At the initial state, the water molecular are adsorbed on $\mathrm{V}$ 
(a)

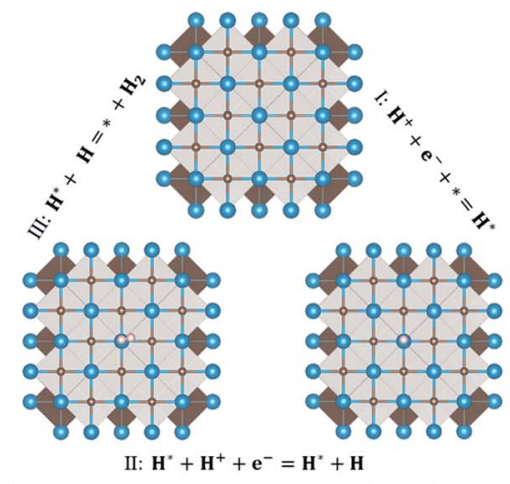

(c)

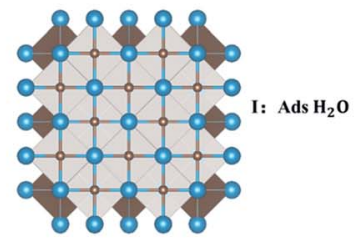

IV: $\mathrm{H}_{2} \mathrm{O}+\mathbf{e}^{-}+\mathrm{H}^{*}={ }^{*}+\mathrm{OH}^{-}+\mathrm{H}_{2}$

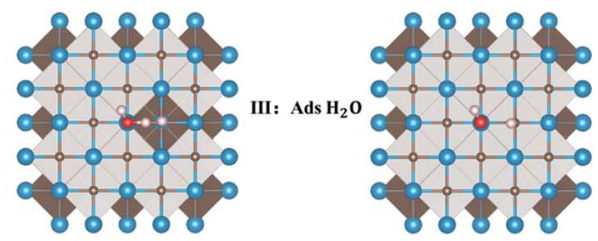

(b)

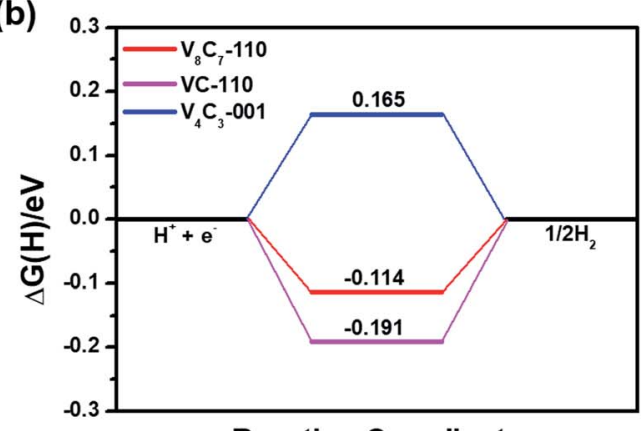

Reaction Coordinate

(d)

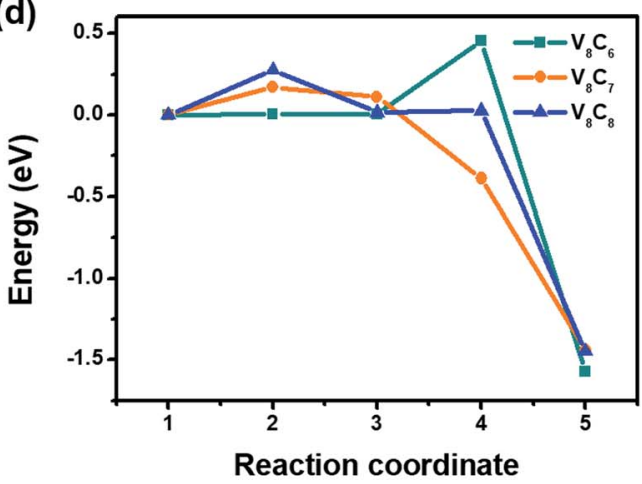

Fig. 3 (a) Hydrogen evolution reaction (HER) process in acidic media. (b) Calculated Gibbs free energy curve of vanadium carbides. (c) HER process in alkaline media. (d) Energy barriers for splitting water.

atom sites. Subsequently, one hydrogen atom of water molecular approaches $\mathrm{C}$ atom and form $\mathrm{C}-\mathrm{H}$ bond in the transition states (TS). Eventually, at the final state, water molecular splits into $\mathrm{H}^{*}$ and $\mathrm{OH}^{*}$. The transition state $4\left(\mathrm{TS}_{4}\right)$ for $\mathrm{V}_{4} \mathrm{C}_{3}$ and transition state $2\left(\mathrm{TS}_{2}\right)$ for $\mathrm{V}_{8} \mathrm{C}_{7}$ and $\mathrm{VC}$ requires the highest energy in their own decomposition processes. These states mark the boundary beyond which the water molecules decompose. $\mathrm{TS}_{2}$ for $\mathrm{V}_{8} \mathrm{C}_{7}$ requests lower energy $(0.169 \mathrm{eV})$ compared to $\mathrm{TS}_{2}$ in $\mathrm{VC}(0.227 \mathrm{eV})$ and $\mathrm{TS}_{4}$ for $\mathrm{V}_{4} \mathrm{C}_{3}(0.454 \mathrm{eV})$. This implies that $\mathrm{V}_{8} \mathrm{C}_{7}$ also exhibit better catalytic performance in alkaline condition among these three systems.

To gain further insight into the catalytic performance of vanadium carbides, we additionally analyzed the oxygen evolution reaction (OER) process of these systems. Four electrons are involved in the production of oxygens by water oxidation: $2 \mathrm{H}_{2} \mathrm{O} \rightarrow \mathrm{O}_{2}+4 \mathrm{H}^{+}+4 \mathrm{e}^{-}$(the detailed reaction steps are listed in ESI $\uparrow$ Section 3). Commonly, over-potential $(\eta), \eta=$ $\max (\Delta G 1, \Delta G 2, \Delta G 3, \Delta G 4) / e-1.23 \mathrm{~V}$, is used to asses OER activity, and $1.23 \mathrm{~V}$ is the over-potential for water oxidation at ambient condition $(T=298.15 \mathrm{~K}, P=1 \mathrm{bar}, \mathrm{pH}=0))^{32}$ Herein, we analyzed the activity of (001), (110) and (111) surfaces of $\mathrm{V}_{4} \mathrm{C}_{3}, \mathrm{~V}_{8} \mathrm{C}_{7}$ and VC. The calculated free energy diagrams and energy values are presented in Fig. 4 and Table $S 5 . \dagger$ For $\mathrm{V}_{4} \mathrm{C}_{3}$, all the reaction steps in (001) plane climb uphill when no potential is applied $(U=0 \mathrm{~V}$, see Fig. 4(a)). Whereas for its (110) and (111) planes, both downhill and uphill states are seen (Fig. 4(b) and (c)). The over-potentials for these three surfaces are obtained to be $1.55 \mathrm{~V}, 6.505 \mathrm{~V}$, and $6.667 \mathrm{~V}$, respectively when the equilibrium potential $(U=1.23 \mathrm{~V})$ is applied (detailed results are displayed in Table S5 $\dagger$ ). Similar characteristics are found for VC and $\mathrm{V}_{8} \mathrm{C}_{7}$ (see Fig. 4(d)-(i)). For these vanadium carbides, their (001) surfaces have smaller $\eta$ values $(1.55 \mathrm{~V}, 1.803 \mathrm{~V}$ and $1.7 \mathrm{~V})$, which suggests that their (001) surfaces exhibit higher catalytic performance for OER. The (110) and (111) surfaces carry smaller negative adsorption energies in $\mathrm{O}^{*}, \mathrm{OH}^{*}$ and $\mathrm{OOH}^{*}$ steps (see Table S5 $\dagger$ ). Therefore, a larger reaction energy barrier and overpotential appear between $\mathrm{OH}^{*}$ and $\mathrm{O}_{2}$ processes, which hinders the releasement of oxygen from the electrode surfaces. Overall, the over-potentials are relatively large when compared to that of $\mathrm{RuO}_{2}(0.37 \mathrm{~V})$ and $\mathrm{IrO}_{2}(0.56 \mathrm{~V}){ }^{33}$ This indicates that vanadium carbides are not suitable for OER catalysts.

As discussed above, our calculations indicate that $\mathrm{V}_{8} \mathrm{C}_{7}$ shows better HER performance than $\mathrm{V}_{4} \mathrm{C}_{3}$ and $\mathrm{VC}$ both in acidic and alkaline media, but the exact origin is rather unclear till now. To resolve this mystery, we further studied the surface energies, hydrogen adsorption energies $\left(\Delta E_{\mathrm{H}^{*}}\right)$, crystal formation energies of these vanadium carbides. The results are displayed in Fig. 5 and also listed in Tables S6 and S7. $\dagger$ As shown in Fig. 5(a), much higher surface energies are observed on (110) and (111) surfaces than (001) surface in all systems. Thus higher activity is expected on (110)/(111) surfaces and ionized hydrogen/oxygen species can be captured more easily on these two faces. More importantly, it is clear that $\mathrm{V}_{8} \mathrm{C}_{7}$ holds the highest surface energy records on all surfaces, which adds one 

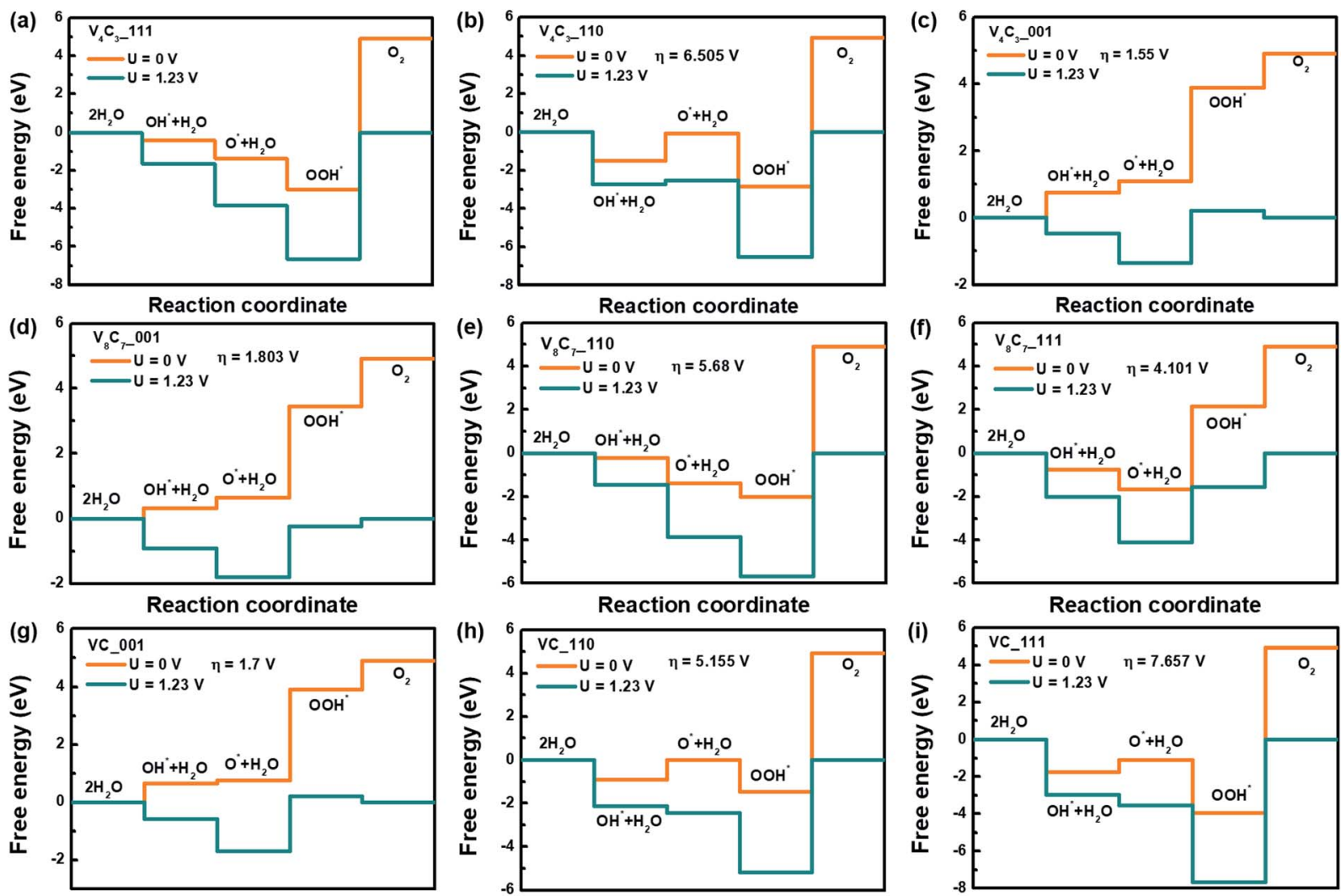

Reaction coordinate

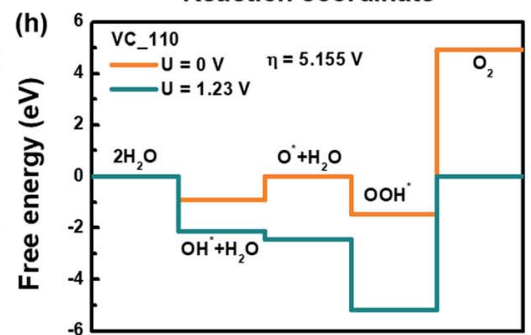

Reaction coordinate

Reaction coordinate

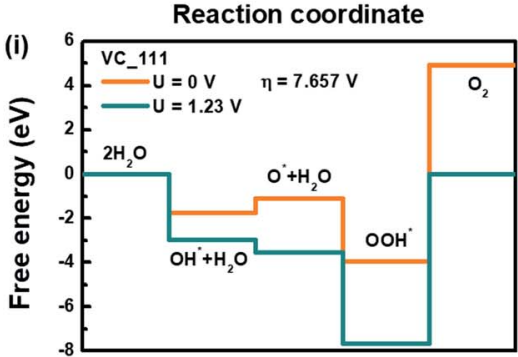

Reaction coordinate

Fig. 4 Free energy diagrams of the OER process of $V_{4} C_{3}, V_{8} C_{7}$ and $V C$. (a-c), $(d-f)$, and $(g-i)$ are (001), (110) and (111) surfaces of $V_{4} C_{3}, V C$ and $\mathrm{V}_{8} \mathrm{C}_{7}$.

(a)

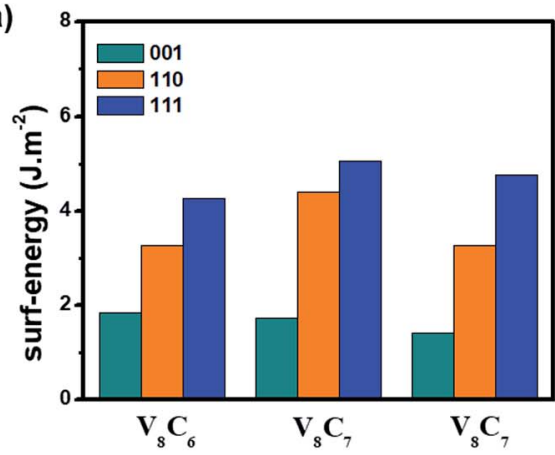

(c)

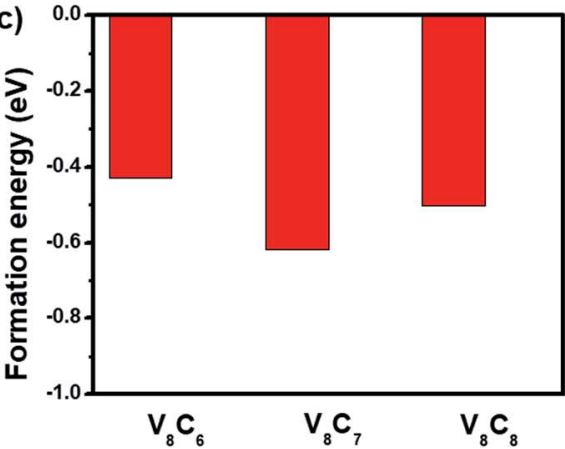

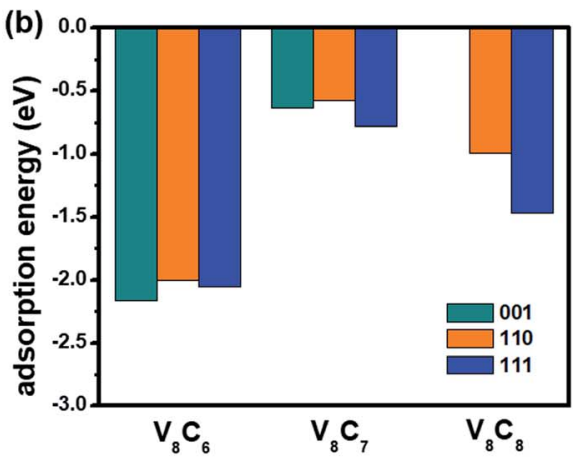

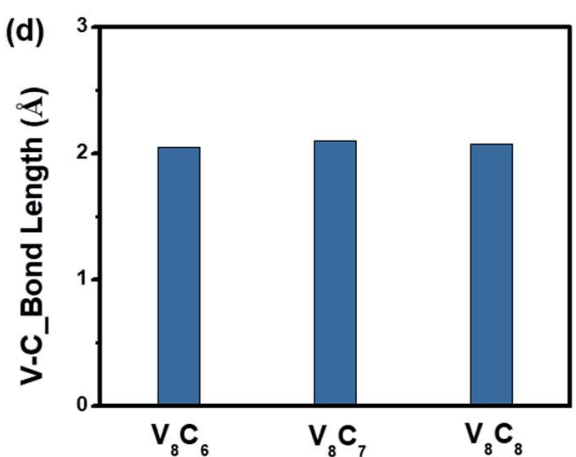

Fig. 5 (a) Calculated surface energies $(001,110,111)$ of vanadium carbons. (b) Adsorption energies of $\mathrm{H}$ atom curve of vanadium carbides, (c) crystal formation energy of vanadium carbides, (d) $V-C$ bond length of $V_{8} C_{6}(001), V_{8} C_{7}(110)$ and $V_{8} C_{8}$ (111) surfaces. 
(a)

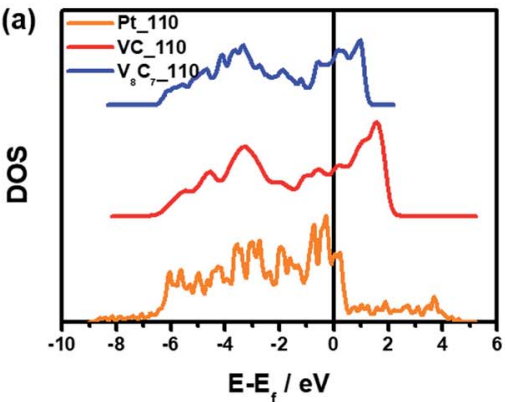

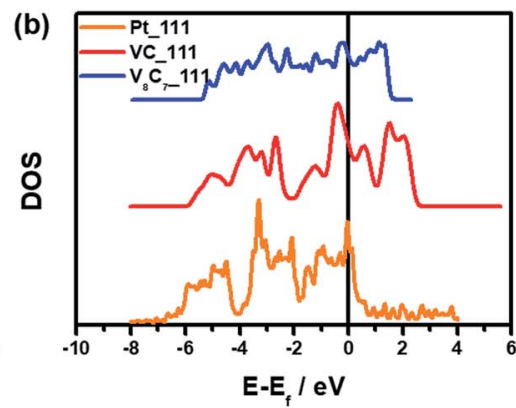

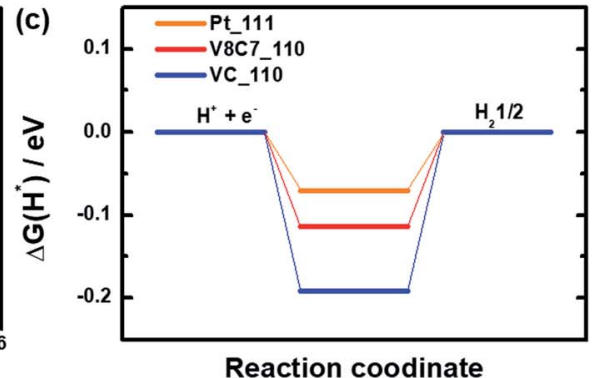

Reaction coodinate

Fig. 6 (a) and (b) are calculated DOS of $\mathrm{VC}, \mathrm{V}_{8} \mathrm{C}_{7}$ and Pt on their (110) and (111) surfaces. Curves are shifted vertically for clarity. (c) $\left|\Delta G\left(H^{*}\right)\right|$ values of $\mathrm{VC}, \mathrm{V}_{8} \mathrm{C}_{7}$ and $\mathrm{Pt}$

score point to outweigh $\mathrm{V}_{4} \mathrm{C}_{3}$ and $\mathrm{VC}$ in $\mathrm{HER}$ performance competition. Apart from the free energy $\Delta G\left(\mathrm{H}^{*}\right)$, hydrogen adsorption energy $\Delta E_{\mathrm{H}^{*}}$ is another criterion to evaluate catalytic performance. In principle, the first step (Volmer) in HER favors negative and small amplitudes for $\Delta E_{\mathrm{H}^{*}}$, whereas positive and large magnitude of $\Delta E_{\mathrm{H}^{*}}$ is more friendly in the second step (Tafel or Heyrovsky). Thus, an appropriate balance of $\Delta E_{\mathrm{H}^{*}}$ close to zero has to be achieved for an excellent catalyst. Fig. 5(b) presents the calculated hydrogen adsorption energies of vanadium carbides. One can see that the hydrogen adsorption energies for $\mathrm{V}_{8} \mathrm{C}_{7}\left(\Delta E_{\mathrm{H}^{*}} \sim-0.5 \mathrm{eV}\right.$ to $\left.-0.7 \mathrm{eV}\right)$ is in close proximity to the zero-balance point on all surfaces. While the values of $\Delta E_{\mathrm{H}^{*}}$ for $\mathrm{V}_{4} \mathrm{C}_{3}(\sim-2 \mathrm{eV})$ and $\mathrm{VC}(\sim-1.5 \mathrm{eV})$ is quite far away from the neutron line. This disadvantage again pushes $\mathrm{V}_{4} \mathrm{C}_{3}$ and $\mathrm{VC}$ behind, while $\mathrm{V}_{8} \mathrm{C}_{7}$ scores one more point in HER performance. Now we come to the crystal formation energy $\left(E_{\mathrm{f}}\right)$ and $\mathrm{V}-\mathrm{C}$ bond length, as presented in Fig. 5(c) and (d) and Table S7. $\dagger$ Apparently, smaller $E_{\mathrm{f}}$ is seen for $\mathrm{V}_{8} \mathrm{C}_{7}\left(E_{\mathrm{f}}=-0.617 \mathrm{eV}\right)$ when compared to $\mathrm{V}_{4} \mathrm{C}_{3}\left(E_{\mathrm{f}}=-0.429 \mathrm{eV}\right)$ and $\mathrm{VC}\left(E_{\mathrm{f}}=-0.502\right.$ $\mathrm{eV}$ ), which allows the easier occurrence of $\mathrm{C}$ vacancies in $\mathrm{V}_{8} \mathrm{C}_{7}$. Formation of $\mathrm{C}$ defects distorts $\mathrm{V}-\mathrm{C}$ bonds (see Fig. S6†), which enhances specific surface area and provides more active sites. These effects add one more bonus to $\mathrm{V}_{8} \mathrm{C}_{7}$. According to bond valence theory, bond length is a measure of bond strength. The larger the bond length, the weaker the bond strength. Fig. 5(d) shows the $\mathrm{V}-\mathrm{C}$ bonds lengths, which tells that $\mathrm{V}_{8} \mathrm{C}_{7}$ has the largest bond length $\left(\mathrm{V}_{8} \mathrm{C}_{7}: 2.10 \AA>\right.$ VC: $\left.2.076 \AA>\mathrm{V}_{4} \mathrm{C}_{3}: 2.055 \AA\right)$. Thus, weaker bond strength is expected in $\mathrm{V}_{8} \mathrm{C}_{7}$ according to the bond valence theory, ${ }^{34}$ which also contributes to the aforementioned smaller hydrogen adsorption energy $\Delta E_{\mathrm{H}^{*}}$. All these factors, including higher surface energy, better hydrogen adsorption energy, lower crystal formation energy (enhanced specific surface area, more active sites) and weaker bond strength contribute additively to the total HER catalytic performance, provide a solid background for $\mathrm{V}_{8} \mathrm{C}_{7}$ to win the contest among these vanadium carbides.

Finally, in Fig. 6, we compare these vanadium carbides with the noble metal catalyst Pt by means of the density of states (DOS) and free energy $\left|\Delta G\left(\mathrm{H}^{*}\right)\right|$. It is clear that the characteristic of DOS for $\mathrm{V}_{8} \mathrm{C}_{7}$ and $\mathrm{VC}$ on (110) and (111) surfaces are rather similar to those of Pt (see Fig. 6(a) and (b)). In both vanadium carbides and Pt systems, most electronic states are located between $-6 \mathrm{eV}$ and $3 \mathrm{eV}$ relative to the Fermi level and all of them are metallic. Moreover, the d-band states of both (110) and (111) surfaces in $\mathrm{V}_{8} \mathrm{C}_{7}$ and $\mathrm{VC}$ appear to resemble those of Pt. Indeed, as shown in Fig. 6(c), the resulting best $\left|\Delta G\left(\mathrm{H}^{*}\right)\right|$ values of $\mathrm{V}_{8} \mathrm{C}_{7}(-0.114 \mathrm{eV},(110)$ surface) and $\mathrm{VC}(-0.191 \mathrm{eV},(111)$ surface) are in close proximity to $\mathrm{Pt}(-0.085 \mathrm{eV},(111)$ surface $){ }^{35}$ It is fair to state that vanadium carbides $\mathrm{V}_{8} \mathrm{C}_{7}$ and $\mathrm{VC}$ belong to the 'noble metal catalysis' and posses Pt-like HER mechanism.

\section{Conclusion}

In summary, first-principles calculation method has been used to systematically analyze the crystal structures, electronic properties, free energies of HER and OER process, surface energies and crystal formation energies of three types of vanadium carbides, i.e., $\mathrm{V}_{4} \mathrm{C}_{3}, \mathrm{~V}_{8} \mathrm{C}_{7}$ and $\mathrm{VC}$. It is found that vanadium carbides display excellent HER performance but poor OER activity. In particular, $\mathrm{V}_{8} \mathrm{C}_{7}$ wins the championship in HER performance among these vanadium carbides. We attribute the exceptional catalytic activity in $\mathrm{V}_{8} \mathrm{C}_{7}$ compared to $\mathrm{V}_{4} \mathrm{C}_{3}$ and $\mathrm{VC}$ to the following factors: (I) larger surface energies trap the ionized hydrogen/oxygen species more easily. (II) More suitable hydrogen adsorption energy $\Delta E_{\mathrm{H}^{*}}$ boost the HER steps. (III) Lower crystal formation energy and easier formation of $\mathrm{C}$ defects increase specified surface area, active sites and provide faster charge transport for HER. (IV) Larger V-C bond length and weaker bond strength contribute to the appearance of proper hydrogen adsorption energy and smaller free energy $\left|\Delta G\left(\mathrm{H}^{*}\right)\right|$. In addition, the remarkable resemblance between $\mathrm{VC} / \mathrm{V}_{8} \mathrm{C}_{7}$ and $\mathrm{Pt}$ in their d-band density of states on (110) and (111) surfaces implies that the HER mechanism of vanadium carbides is Pt-like. Our findings thus bring new insight to the theoretical understanding of the excellent HER performance of vanadium carbides.

\section{Conflicts of interest}

The authors declare no competing financial interests.

\section{Acknowledgements}

Mingquan He acknowledges support by Fundamental Research Funds for the Central Universities (2018CDJDWL0011), China. 
Jing Wan acknowledges the support by the National Natural Science Foundation of China under Grant No. 11774142, and Shenzhen Basic Research Fund under Grant No. JCYJ20170817105201098, JCYJ20180504165817769, and JCYJ20170817105132549. The computer time was supported by the Center for Computational Science and Engineering of Southern University of Science and Technology.

\section{References}

1 X. Zou and Y. Zhang, Chem. Soc. Rev., 2015, 44, 5148-5180. 2 S. Dunn, Int. J. Hydrogen Energy, 2002, 27, 235-264.

3 D. B. Putungan, S. H. Lin and J. L. Kuo, Phys. Chem. Chem. Phys., 2015, 17, 21702-21708.

4 J. Zhang, T. Wang, P. Liu, Z. Liao, S. Liu, X. Zhuang, M. Chen, E. Zschech and X. Feng, Nat. Commun., 2017, 8, 15437.

5 M. S. Faber and S. Jin, Energy Environ. Sci., 2014, 7, 35193542.

6 S. R. Chemler and M. T. Bovino, ACS Catal., 2013, 3, 10761091.

7 Y. C. Kimmel, X. Xu, W. Yu, X. Yang and J. G. Chen, ACS Catal., 2014, 4, 1558-1562.

8 Q. Gao, W. Zhang, Z. Shi, L. Yang and Y. Tang, Adv. Mater., 2019, 31, e1802880.

9 M. Miao, J. Pan, T. He, Y. Yan, B. Y. Xia and X. Wang, Chemistry, 2017, 23, 10947-10961.

10 R. Wang, J. Yang, K. Shi, B. Wang, L. Wang, G. Tian, B. Bateer, C. Tian, P. Shen and H. Fu, RSC Adv., 2013, 3, 4117.

11 Y. Xi, L. Huang, R. C. Forrey and H. Cheng, RSC Adv., 2014, 4, 39912.

12 C. Wan, Y. N. Regmi and B. M. Leonard, Angew. Chem., Int. Ed., 2014, 53, 6407-6410.

13 H. Vrubel and X. Hu, Angew. Chem., Int. Ed., 2012, 51, 1270312706.

14 J. Wan, Q. Liu, T. Wang, H. Yuan, P. Zhang and X. Gu, Solid State Commun., 2018, 284-286, 25-30.

15 M. Boudart and R. B. Levy, Science, 1973, 181, 547-549.

16 S. Wirth, F. Harnisch, M. Weinmann and U. Schröder, Appl. Catal., B, 2012, 126, 225-230.
17 W. F. Chen, J. T. Muckerman and E. Fujita, Chem. Commun., 2013, 49, 8896-8909.

18 J. Zhu, K. Sakaushi, G. Clavel, M. Shalom, M. Antonietti and T. P. Fellinger, J. Am. Chem. Soc., 2015, 137, 5480-5485.

19 J. Jin, Z. Wei, X. Qiao, H. Fan and L. Cui, RSC Adv., 2017, 7, 26710-26716.

20 X. Peng, L. Hu, L. Wang, X. Zhang, J. Fu, K. Huo, L. Y. S. Lee, K.-Y. Wong and P. K. Chu, Nano Energy, 2016, 26, 603-609.

21 Y. N. Regmi, G. R. Waetzig, K. D. Duffee, S. M. Schmuecker, J. M. Thode and B. M. Leonard, J. Mater. Chem. A, 2015, 3, 10085-10091.

22 H. Xu, J. Wan, H. Zhang, L. Fang, L. Liu, Z. Huang, J. Li, X. Gu and Y. Wang, Adv. Energy Mater., 2018, 8, 1800575.

23 G. Kresse and J. Hafner, Phys. Rev. B: Condens. Matter Mater. Phys., 1993, 47, 558-561.

24 G. K. D. Joubert, Phys. Rev. B: Condens. Matter Mater. Phys., 1999, 59, 1758.

25 J. P. Perdew, K. Burke and M. Ernzerhof, Phys. Rev. L, 1996, 77, 3865-3868.

26 H. J. Monkhorst and J. D. Pack, Phys. Rev. B: Solid State, 1976, 13, 5188-5192.

27 S. Smidstrup, A. Pedersen, K. Stokbro and H. Jonsson, J. Chem. Phys., 2014, 140, 214106.

28 J. K. Nørskov, T. Bligaard, A. Logadottir, J. R. Kitchin, J. G. Chen, S. Pandelov and U. Stimming, J. Electrochem. Soc., 2005, 152(5), J23-J26.

29 M. H. M. Rahal, A. El Hammadi, M. El Mouhtadi and A. El Hajbi, J. Mol. Struct.: THEOCHEM, 2000, 572, 73-80.

30 Y. L. Bin Wang and J. Ye, Phys. Scr., 2013, 88, 015301.

31 P. G. M. Berit Hinnemann, J. Bonde, K. P. Jørgensen, J. H. Nielsen, S. Horch, I. Chorkendorff and J. K. Nørskov, J. Am. Chem. Soc., 2005, 127, 5308-5309.

32 M. Bajdich, M. Garcia-Mota, A. Vojvodic, J. K. Norskov and A. T. Bell, J. Am. Chem. Soc., 2013, 135, 13521-13530.

33 J. Rossmeisl, Z. W. Qu, H. Zhu, G. J. Kroes and J. K. Nørskov, J. Electroanal. Chem., 2007, 607, 83-89.

34 I. D. Brown, Acta Crystallogr., Sect. A: Found. Crystallogr., 2007, 63, 374.

35 J. Greeley and J. K. Nørskov, Surf. Sci., 2007, 601, 1590-1598. 